\title{
Inovação e administração estratégica para os novos cenários competitivos do século XXI
}

\author{
Innovation and strategic management for the new \\ competitive scenarios of the $21^{\text {st }}$ century
}

\section{Claudia Mara Vicentine}

Doutoranda pela Universidad Nacional de Misiones (UNAM), administradora de empresas, Universidade da Indústria (Unindus), Curitiba, PR - Brasil, e-mail: cvicentine@gmail.com

\section{Resumo}

Este estudo aborda uma análise contextual e estratégica do tema "inovação", tendo como objetivo despertar essa temática pouco explorada, sobretudo perante as instituições de ensino superior, o que é essencial, pois os formandos de hoje serão os gestores, colaboradores e empresários de amanhã e, sem dúvida, deverão superar muitas adversidades ambientais, que dificultarão o cumprimento dos objetivos organizacionais, além da necessidade de uma formação profissional mais completa para que, com a sua colaboração em termos macro, possam efetivamente atuar como elementos atuantes do desenvolvimento socioeconômico do país perante os atuais cenários estratégicos. Foi utilizada como método a pesquisa descritiva, com este artigo abordando o conceito de inovação, os seus mandamentos, as três formas de se realizar a mudança nas organizações, o processo de criação das organizações e o case do Cirque du Soleil, com isso abordou-se mais o aspecto da inovação em produtos, mas há de se estudar e analisar futuramente a questão da inovação por processos e a por serviços.

Palavras-chave: Inovação. Estratégia. Cenários. Mudança. Cirque du Soleil.

\begin{abstract}
This study focuses on a contextual analysis of "innovation" and strategic theme, the objective was to wake up this issue explored, particularly against the institutions of higher education which is essential because the students of
\end{abstract}


today are the managers, employees and entrepreneurs of tomorrow, and which undoubtedly must overcome many environmental adversity that impede the achievement of organizational objectives, beyond the need for a more complete training for that with their collaboration in macro can effectively act as active agents of socioeconomic development of the country, before the current scenarios strategic. Was used as a descriptive method, and this article discusses the concept of innovation, and his commandments, the three ways to effect change in organizations, the creation process of organizations and the case of Cirque du Soleil, it approached is more the aspect of product innovation, but there to study and analyze the issue of future innovation by process and by services.

Keywords: Innovation. Strategy. Sceneries. Change. Cirque du Soleil.

\section{Introdução}

O presente estudo apresenta uma análise contextual e estratégica sobre o tema "inovação" (Figura 1). Trata-se de uma pesquisa descritiva, que tem como referência Scandura e Williams (2000) e que objetiva despertar essa temática pouco explorada, sobretudo perante as instituições de ensino superior, o que é essencial, pois os formandos de hoje serão os gestores, colaboradores e empresários de amanhã e, sem dúvida, deverão superar muitas adversidades ambientais que dificultarão o cumprimento dos objetivos organizacionais, além da necessidade de uma formação profissional mais completa para que, com a sua colaboração em termos macro, possam efetivamente atuar como elementos atuantes do desenvolvimento socioeconômico do país perante os atuais cenários estratégicos.

A palavra inovar, que vem do latim, significa tornar novo, renovar. Enquanto inovação, traduz-se pelo ato de inovar. De acordo com o Novo Dicionário Aurélio (2009), inovar é a ação ou o efeito de inovar; introdução de alguma novidade na legislação, nos costumes, na ciência, nas artes, etc. Quanto ao seu resultado, normalmente muitos desconfiam, porém, isso faz parte da renovação. Segundo o Guia Valor Econômico de inovação nas empresas, "inovaré ter umaidéia que seus concorrentes ainda não tiveram e implantála com sucesso. A inovação faz parte da estratégia das empresas: seu foco é o desempenho econômico e a criação de valor" (LIPPI; SIMANTOB, 2003).

\section{Autores importantes e suas percepções sobre inovação}

No Quadro 1, observam-se vários posicionamentos referentes à inovação de acordo com as óticas de alguns autores da atualidade.
Nas palavras de Gibson e Skarzynski (2008), o objetivo da inovação não é apenas "produzir milhares de flores", mas garantir que elas sejam plantadas de maneira ordenada, no mesmo jardim, por assim dizer. Em vez de atirar em várias direções, a meta é produzir milideias e oportunidades de alta qualidade, nas áreas escolhidas para o foco estratégico.

Os estudos dos cenários sinalizam dificuldades da área operacional nas organizações e, para solucionar essas dificuldades, caberão as soluções estratégicas inovadoras; afinal, o ato de administrar é um desafio permanente. Não há fórmulas prontas, mas sim a necessidade de uma discussão permanente, que deverá buscar analisar alternativas caso a caso.

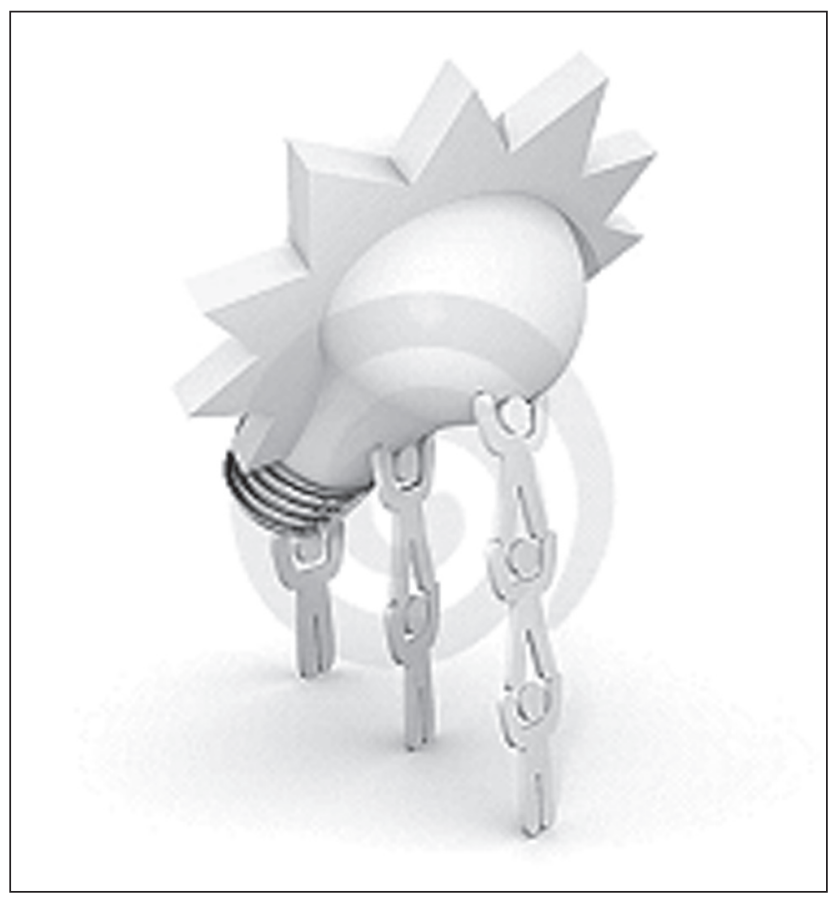

Figura 1 - Inovação

Fonte: INNOVATION, 2010. 


\begin{tabular}{|c|c|c|}
\hline Autor-Data & Instituição & Conceito \\
\hline $\begin{array}{l}\text { C. K. Prahalad } \\
(1990)\end{array}$ & $\begin{array}{l}\text { Universidade de } \\
\text { Michigan }\end{array}$ & $\begin{array}{l}\text { Inovação é adotar novas tecnologias que permitem aumentar a } \\
\text { competitividade da companhia. }\end{array}$ \\
\hline $\begin{array}{l}\text { Ernest Gundling } \\
\text { (1999) }\end{array}$ & $3 \mathrm{M}$ & $\begin{array}{l}\text { Inovação é uma nova ideia, implementada com sucesso, que produz } \\
\text { resultados econômicos. }\end{array}$ \\
\hline Fritjof Capra & $\begin{array}{l}\text { Universidade de } \\
\text { Berkeley }\end{array}$ & As organizações inovadoras são aquelas que se aproximam do limite do caos. \\
\hline Gary Hamel (2001) & (Strategos) & $\begin{array}{l}\text { Inovação é um processo estratégico de reinvenção contínua do próprio } \\
\text { negócio e da criação de novos conceitos de negócios. }\end{array}$ \\
\hline $\begin{array}{l}\text { Giovanni Dosi } \\
(1988)\end{array}$ & Universidade de Pisa & $\begin{array}{l}\text { Inovação é a busca, descoberta, experimentação, desenvolvimento, imitação e } \\
\text { adoção de novos produtos, novos processos e novas técnicas organizacionais. }\end{array}$ \\
\hline $\begin{array}{l}\text { Guilherme Ary } \\
\text { Plonski }\end{array}$ & $\begin{array}{l}\text { Instituto de Pesquisas } \\
\text { Tecnológicas }\end{array}$ & $\begin{array}{l}\text { Inovação pode ter vários significados e a sua compreensão depende do } \\
\text { contexto em que ela for aplicada. Pode ser ao mesmo tempo resultado e } \\
\text { processo ou ser associada à tecnologia ou marketing. }\end{array}$ \\
\hline $\begin{array}{l}\text { Joseph Schumpeter } \\
\text { (1982) }\end{array}$ & & A inovação caracteriza-se pela abertura de um novo mercado. \\
\hline Vico Mañas (1993) & & $\begin{array}{l}\text { Inovar consiste em nos preocupar com algo que nunca foi feito antes, } \\
\text { ou seja, desenvolver estudos, fazer investimentos, despender tempo em } \\
\text { criatividade, planejamento, controle e coordenação, para, ao final, obtermos } \\
\text { algo totalmente novo. Isso tudo pela necessidade de ser competitivo, de } \\
\text { manter-se vivo ou para manter-se à frente dos concorrentes. }\end{array}$ \\
\hline $\begin{array}{l}\text { Martin Bell e } \\
\text { Keith Pavitt }\end{array}$ & $\begin{array}{l}\text { Universidade de } \\
\text { Sussex }\end{array}$ & $\begin{array}{l}\text { A inovação pode ser vista como um processo de aprendizagem } \\
\text { organizacional. }\end{array}$ \\
\hline $\begin{array}{l}\text { Peter Drucker } \\
(1989)\end{array}$ & $\begin{array}{l}\text { Universidade de } \\
\text { Claremont }\end{array}$ & $\begin{array}{l}\text { É o instrumento específico dos empreendedores, o processo pelo qual eles } \\
\text { exploram a mudança como uma oportunidade para um negócio diferente } \\
\text { ou um serviço diferente. Inovação é o ato de atribuir novas capacidades aos } \\
\text { recursos (pessoas e processos) existentes na empresa para gerar riqueza. }\end{array}$ \\
\hline Price Pritchett & $\begin{array}{l}\text { Consultoria Price } \\
\text { Pritchett }\end{array}$ & $\begin{array}{l}\text { Inovação é como nós nos mantemos à frente do nosso ambiente. As } \\
\text { inovações fora da nossa organização vão acontecer 'quando elas quiserem' - } \\
\text { estejamos prontos ou não. }\end{array}$ \\
\hline $\begin{array}{l}\text { Ronald Jonash e } \\
\text { Tom Sommerlatte } \\
(2001)\end{array}$ & & $\begin{array}{l}\text { Inovação é um processo para alavancar a criatividade a fim de criar valor } \\
\text { de novas maneiras, por meio de novos produtos, novos serviços e novos } \\
\text { negócios. }\end{array}$ \\
\hline Tom Kelley (2000) & Ideo & Inovação é o resultado de um esforço de time. \\
\hline
\end{tabular}

Quadro 1 - Autores importantes e suas definições sobre inovação Fonte: LIPPI; SIMANTOB, 2003.

O conceito de inovação estratégica difere dos conceitos de inovação sustentadora e disruptiva, ${ }^{1}$ na medida em que as inovações estratégicas podem oferecer desempenho superior ou inferior em atributos valorizados pelos clientes. Elas podem almejar os clientes existentes ou um novo segmento de clientes e podem ameaçar ou não o negócio principal. As inovações estratégicas envolvem o teste de novas respostas,

1 É um termo descrevendo a inovação tecnológica, o produto ou o serviço que utiliza uma estratégia "disruptiva", em vez de "revolucionário" ou "evolucionário", para derrubar uma tecnologia existente dominante no mercado. 
significativamente diferentes, a pelo menos três questões fundamentais sobre a estratégia: quem é o cliente? Qual o valor oferecido ao cliente? Como esse valor é fornecido? (GOVINDARAJAN; TRIMBLE, 2005).

\section{Os 10 mandamentos para promover a inovação ${ }^{2}$}

1) Reconheça os mais criativos.

- Recompense a criatividade de forma concreta e definitiva.

- Reconheça a criatividade abaixo da linha de gerência.

- Encoraje os subordinados a recompensar a criatividade.

2) Assuma riscos consideráveis.

- Somente riscos altos trazem retornos satisfatórios.

- Muitas ideias deixam de ser absurdas quando analisadas por outro ponto de vista.

- Assuma e deixe que outros assumam riscos, tolerando erros provenientes de um esforço honestamente criativo. Em geral, são eles que trazem grandes retornos.

3) Vença os obstáculos e não se deixe vencer.

- Obstáculos são inerentes ao processo criativo.

- Obstáculos são vencidos pela perseverança.

- Aceite as perdas de curto prazo para ter ganhos a longo prazo.

- Ideias criativas não se vendem facilmente. Seja perseverante na defesa de suas ideias ou propostas.

4) Pense a longo prazo.

- O preço de resultados a curto prazo é a perda da inovação.

- Tenha duas estratégias separadas - curto prazo e longo prazo.
- Não sacrifique a pesquisa básica em função da aplicada.

- Criatividade genuína requer longo prazo.

- Pense estrategicamente e não apenas taticamente; seja proativo e não reativo.

5) Continue crescendo.

- Não seja complacente pelo sucesso inicial.

- Nem todas as ideias criativas são imortais.

- Não se acomode no sucesso de hoje e se desligue do sucesso do passado.

- Mantenha o foco no amanhã.

6) Cuidado com a falta de conhecimento ou com o conhecimento em demasia.

- Em P\&D, a falta de conhecimento pode ser fatal.

- Deve-se saber o que está acontecendo no campo de atuação.

- Para crescer, há a necessidade de variedade e amplitude de conhecimento.

- Excesso de conhecimento específico é tão perigoso quanto a falta dele. Os maiores erros são cometidos por experts.

7) Tolere as ambiguidades.

- Ideias criativas surgem subitamente, mas são desenvolvidas lentamente. É como montar um quebra-cabeças.

- Aprenda a tolerar a ambiguidade e a frustração de resolver problemas e de tomar decisões.

- As ideias mais criativas vêm de pessoas com capacidade de esperar. Os resultados justificam a frustração da espera.

8) Reformule problemas sem solução.

- Muitas ideias criativas são provenientes de problemas sem solução à primeira vista.

- Quando um problema se mostra sem solução, tente reformulá-lo.

- As maiores dificuldades em resolver um problema vêm da maneira como esse

2 Fonte: GUNDLING, 1999. 
problema é abordado e não da falta de soluções.

9) Faça o que você mais gosta de fazer.

- As ideias mais criativas vêm de pessoas que amam o que fazem.

- Não há substituto para a motivação intrínseca.

- A motivação por si só não traz a inovação, mas a sua falta garante a ausência dela.

- Se for possível, mude a pessoa para uma função que seja mais adequada aos seus talentos.

10) Reconheça quando moldar o ambiente e quando deixá-lo.

- Mudar o ambiente é mais fácil para a gerência de topo.

- É uma tarefa árdua e lenta que exige mudanças incrementais.

- Seisso for impossível, mude de ambiente ou de companhia.

- Criatividade exige comprometimento, o que às vezes requer decisões corajosas.

\section{Mudanças podem e devem ocorrer nas organizações}

Existem basicamente três formas de se realizar a mudança nas organizações: sucintamente, temos "evolução", "revolução" e "inovação", podendo ocorrer simultaneamente ou individualmente, veja:

- por evolução: é mais lenta, pois vai adaptando os ambientes organizacionais de acordo com as circunstâncias de sobrevivência e demandas por melhorias;

- por revolução: são realizadas por propostas e modelos de negócios absolutamente novos, que desestruturam o modelo existente e instalam o novo modelo, que modifica o status existente;

- por inovacão: consiste em introduzir novidades nos negócios organizacionais. Drucker comenta que inovar é um dos grandes um dos mais importantes - objetivos de qualquer organização. Temos a inovação como algo que mantém a empresa viva, competitiva e, em alguns casos, lhe permite dar pulos, ganhando a liderança, estabelecendo novos rumos para toda a concorrência, clientela e fornecedores de maneira geral. A inovação calcada no conhecimento pode levar as organizações a garantias de menos riscos.

Ao longo dos últimos anos, diante desses novos cenários, percebe-se que as organizações trabalharam arduamente para se tornar mais eficientes. Elas promoveram reengenharias, reduziram o pessoal, integraram processos e implantaram programas de qualidade, porém essas ações não trouxeram tranquilidade. O Quadro 2, apresentado na sequência, procura demonstrar o processo de criação das organizações.

\begin{tabular}{lllll}
\hline $\begin{array}{l}\text { Quem são } \\
\text { os clientes? }\end{array}$ & $\begin{array}{l}\text { O que } \\
\text { fornecemos? }\end{array}$ & Como trabalhamos? & $\begin{array}{l}\text { Como ganhamos } \\
\text { dinheiro? }\end{array}$ & $\begin{array}{l}\text { Qual o nosso diferencial } \\
\text { para sustentar uma } \\
\text { vantagem competitiva? }\end{array}$ \\
\hline $\begin{array}{l}\text { Quem são os } \\
\text { clientes? }\end{array}$ & $\begin{array}{l}\text { Quais são os } \\
\text { produtos e serviços } \\
\text { que vendemos? }\end{array}$ & $\begin{array}{l}\text { Quais canais de } \\
\text { distribuição usamos? }\end{array}$ & $\begin{array}{l}\text { O que cobramos de } \\
\text { nossos clientes? }\end{array}$ & $\begin{array}{l}\text { Em que somos diferentes } \\
\text { dos concorrentes? }\end{array}$ \\
$\begin{array}{l}\text { Quais segmentos do } \\
\text { mercado atendemos } \\
\text { em quais locais } \\
\text { geográficos? }\end{array}$ & $\begin{array}{l}\text { Quais benefícios e } \\
\text { soluções oferecemos } \\
\text { aos clientes? }\end{array}$ & $\begin{array}{l}\text { Como está configurada } \\
\text { nossa cadeia de } \\
\text { valores? }\end{array}$ & $\begin{array}{l}\text { Quais são os } \\
\text { principais custos de } \\
\text { produção? }\end{array}$ & Como os clientes sentem diferença? \\
& & & &
\end{tabular}

Quadro 2 - Processo de criação das organizações

(Continua) 


\begin{tabular}{|c|c|c|c|c|}
\hline $\begin{array}{l}\text { Quem são } \\
\text { os clientes? }\end{array}$ & $\begin{array}{l}\text { O que } \\
\text { fornecemos? }\end{array}$ & Como trabalhamos? & $\begin{array}{l}\text { Como ganhamos } \\
\text { dinheiro? }\end{array}$ & $\begin{array}{l}\text { Qual o nosso diferencial } \\
\text { para sustentar uma } \\
\text { vantagem competitiva? }\end{array}$ \\
\hline \multirow[t]{3}{*}{$\begin{array}{l}\text { Quem são os } \\
\text { compradores de } \\
\text { novos produtos e } \\
\text { serviços? }\end{array}$} & & $\begin{array}{l}\text { Quais são os processos } \\
\text { e atividades essenciais } \\
\text { que traduzem nossas } \\
\text { competências, ativos } \\
\text { e outros aspectos que } \\
\text { agregam valor aos } \\
\text { clientes? }\end{array}$ & $\begin{array}{l}\text { Como extraímos } \\
\text { valor? }\end{array}$ & $\begin{array}{l}\text { Quais são as diferenças } \\
\text { que eles mais valorizam? }\end{array}$ \\
\hline & & $\begin{array}{l}\text { Quem são os nossos } \\
\text { parceiros? }\end{array}$ & $\begin{array}{l}\text { Qual é nosso modelo } \\
\text { de definição de preços } \\
\text { (p. ex., preços fixos } \\
\text { ou assinatura, tarifas } \\
\text { próprias ou personali- } \\
\text { zadas, preços diretos } \\
\text { ou indiretos - por meio } \\
\text { de terceiros, pacotes } \\
\text { com itens separados a } \\
\text { la carte, definidos por } \\
\text { nós ou baseados no } \\
\text { mercado, etc.) }\end{array}$ & $\begin{array}{l}\text { Quão sustentável é nosso } \\
\text { diferencial? }\end{array}$ \\
\hline & & $\begin{array}{l}\text { Como nossos } \\
\text { fornecedores e } \\
\text { parceiros nos ajudam a } \\
\text { distribuir valores? }\end{array}$ & & $\begin{array}{l}\text { Ele é protegido por } \\
\text { competências essenciais } \\
\text { e ativos estratégicos } \\
\text { exclusivos? }\end{array}$ \\
\hline
\end{tabular}

Quadro 2 - Processo de criação das organizações (Conclusão) Fonte: GIBSON; SKARZYNSKI, 2008.

Conforme apresentado por Oliveira (1988), os cenários estratégicos "representam critérios e medidas para a preparação do futuro da empresa". Agreguem-se também a essa definição, algumas premissas e características referentes aos cenários estratégicos.

Nesse sentido, é importante perceber o conceito de estratégia de forma ampliada, para que possa permitir a inclusão de forma abrangente para a realidade competitiva emergente. Para Hamel e Prahalad (1995), trata-se de "uma realidade na qual a meia é transformar setores, não apenas organizações; uma realidade na qual ser cada vez melhor não basta; uma realidade na qual uma empresa incapaz de imaginar o futuro não estará lá para desfrutar dele". Assim sendo, faz-se necessário observar os aspectos relevantes à construção dos cenários estratégicos.

\section{Cirque du Soleil: a estratégia e a inovação}

Você já teve a oportunidade de assistir a um show do Cirque du Soleil (Figura 2)? Se ainda não, saiba que você está perdendo muito, e é hora de pensar em aproveitar o espetáculo, inclusive olhando com olhos inovadores e estratégicos!

Nas palavras de Mintzberg (2000), que tipifica os estudos de administração estratégica em dez escolas: Escola do Design; Escola de Planejamento; Escola de Posicionamento; Escola Empreendedora; Escola Cognitiva; Escola de Aprendizado; Escola de Poder; Escola Cultural; Escola Ambiental; e Escola de Configuração. Ainda o mesmo autor se refere às teorias de Michael Porter sobre forças competitivas, estratégias genéricas e cadeia de valor, fazendo parte 


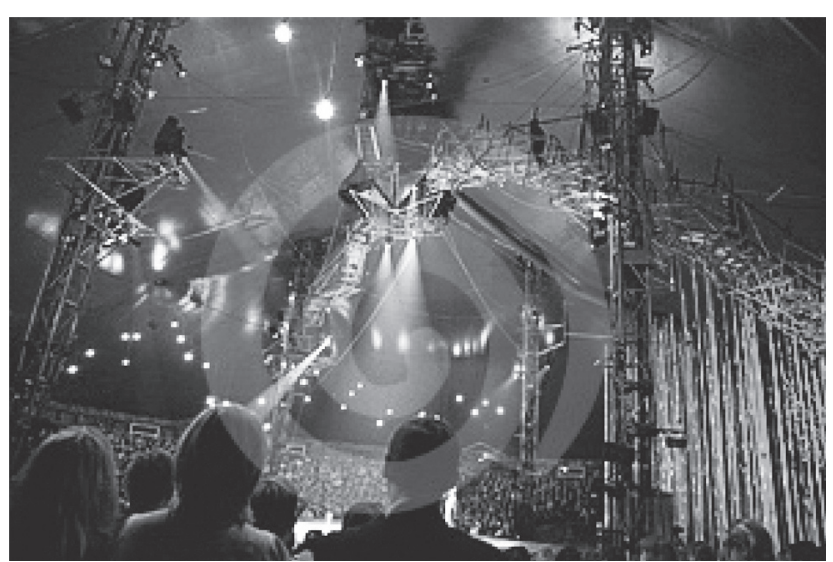

Figura 2 - Espectadores em uma apresentação do Cirque du Soleil

Fonte: SPECTATORS, 2010.

da escola de posicionamento - a escola que define a formação das estratégias como um processo analítico. Todos, pelo menos uma vez na vida, já estiveram em um circo, e o Cirque du Soleil, face às novas adversidades, oportunidades e as transformações culturais, buscou inovar e podemos dizer que reinventou a arte circense. Pergunta-se como, primeiramente, desenvolveu um nível de qualidade e inovação insuperável nos espetáculos, buscando encantar e surpreender o público/cliente e com isso dificultou a ameaças dos entrantes.

Os fornecedores são tratados como parceiros e aliados e o foco é única e exclusivamente o cliente. As equipes multidisciplinares internas e externas fomentam a inovação em todos os seus setores, dessa forma cria-se uma barganha com os fornecedores e cria-se a cumplicidade.

Em relação à barganha com os clientes o Cirque du Soleil procura criar, inovar sem perder o seu foco, que é o cliente, ou seja, eles buscam serem únicos no que fazem, tanto é que clientes/público se disponibilizam a pagar os valores de ingressos que podem ser considerados altos face à realidade brasileira, pois sabem que o que verão lá não será visto em outro lugar... Afinal eles são únicos!

Tendo a inovação como uma característica no DNA do Cirque du Soleil, eles estão sempre a frente, inovando, se recriando, ou seja, criando e desenvolvendo novos produtos, que substituirão outros produtos próprios.

Você deve estar se perguntando sobre a concorrência, pode-se dizer que o Cirque du Soleil atue voltado para um público/mercado específico, portanto não há comparação com outros circos. É como se fosse arte em formato de monopólio. Não há concorrentes diretos.

O Cirque du Soleil possui espetáculos únicos e lucrativos e pode-se dizer que a sua estratégia é a diferenciação, tendo como cadeia de valor atividades primárias, ou seja, as de produção e distribuição e também de suporte, que são aquelas que envolvem recursos humanos, suprimento, tecnologia e de infraestrutura. E, tendo uma cadeia de valor bem gerenciada, o lucro fica quase garantido.

Quando se fala de Cirque du Soleil, podese ver claramente a aplicação dos conceitos e das premissas da eficiência e da eficácia! Tem-se aqui um grande exemplo a ser seguido e estudado pelos administradores.

\section{Considerações finais}

Este trabalho procurou analisar a inovação de forma objetiva e singela, pois há ainda uma mística quando se usa esse termo.

As organizações e as pessoas, de um modo geral, apresentam-se de modo muito arredio quando se fala em inovação. O próprio termo ainda desperta nos gestores e nos demais um pouco de descrédito, porém, é para todas as organizações praticarem-na na sua atividade de gestão, criando mecanismos que podem proporcionar a elaboração de cenários estratégicos e inovadores como um meio de vislumbrar possíveis situações futuras.

Diante do atual quadro de mudanças em que se encontra a globalização, que abre novas portas ao mundo, aos pesquisadores, às pessoas em geral, aos empresários empreendedores, às organizações, às concorrências, às renovações tecnológicas, enfim, a todos que estão inseridos neste contexto atual, além da competitividade e da velocidade, não se pode prescindir do conhecimento e da aplicação dessa tecnologia estratégica, que certamente determinará a capacidade de superação dos desafios ambientais e o desenvolvimento institucional.

Com este artigo, busca-se, também, despertar essa temática pouco explorada, sobretudo diante das instituições de ensino superior, o que é essencial, pois os formandos de hoje serão os gestores/colaboradores/empresários de amanhã e, sem dúvida, deverão superar muitas adversidades ambientais, 
que dificultarão o cumprimento dos objetivos organizacionais, além da necessidade de uma formação profissional mais completa para que, com a sua colaboração em termos macro, possam efetivamente agir como elementos atuantes do desenvolvimento socioeconômico do País.

Neste artigo foi abordado mais o aspecto da inovação em produtos, mas há de se estudar e analisar futuramente a questão da inovação por processos e por serviços. Por fim, buscou-se enfatizar a contribuição à sensibilização dos gestores universitários, devendo ser, na maior brevidade possível, adorada, pois a sua utilização promoverá amplitude de percepção e consequente readaptação da academia face às grandes transformações ambientais, organizacionais e estratégicas perante a inovação.

\section{Referências}

DOSI, G. The nature of the innovative process. Brighton: DRC Discussion Paper SPRU; University of Sussex, 1988.

DRUCKER, P. F. As novas realidades: no governo e na política, na economia e nas empresas, na sociedade e na visão do mundo. 2. ed. São Paulo: Pioneira, 1989.

CIRQUE du Soleil. Fonte: <http://www.cirquedusoleil. com/en/welcome.aspx>. Acesso em: 29 jul. 2010.

GIBSON, R.; SKARZYNSKI, P. Inovação: o caminho para transformações nas organizações. 2. ed. São Paulo: Campus, 2008.

GOVINDARAJAN, V.; TRIMBLE, C. Os 10 mandamentos da inovação estratégica: do conceito à implementação. 2. ed. Rio de Janeiro: Elsevier, 2005.

GUNDLING, E. F. The 3M way to innovation: balancing people and profit. 2nd ed. New York: Vintage Books, 1999.

HAMEL, G. Liderando a revolução. Entrevista concedida para Eduardo Ferraz. Exame, n. 737, p. 88-98, 2001.

HAMEL, C.; PRAHALAD, C. D. Competindo pelo futuro. 2. ed. Rio de Janeiro: Campus, 1995.

INNOVATION - Team lifting light bulb. Disponível em: < http://www.dreamstime.com/stock-photography innovation-team-lifting-light-bulb-image13678892>. Acesso em: 29 jul. 2010.
JONASH, R. S.; SOMMERLATTE, T. O valor da inovação: como as empresas mais avançadas atingem alto desempenho e lucratividade. (The innovation premium). 2. ed. Rio de Janeiro: Campus, 2001.

KELLEY, T. The art of innovation. 2nd ed. New York: Curreney Book, 2000.

LIPPI, R.; SIMANTOB, M. Guia valor econômico de inovação nas empresas. São Paulo: Globo, 2003.

MINTZBERG, H. et al. Safári de estratégias: um roteiro pela selva do planejamento estratégico. 2. ed. Porto Alegre: Bookman, 2000.

NOVO Dicionário Aurélio da Língua Portuguesa. 4. ed. Curitiba: Positivo, 2009.

OLIVEIRA, D. de P.R. de. Estratégia empresarial: uma abordagem empreendedora. 2. ed. São Paulo: Atlas, 1988.

PRAHALAD, C. K.; HAMEL, G. The core competence of the corporation. Harvard Business Review, Boston, v. 68 , p. 79-91, 1990.

SCANDURA, T. A.; WILLIAMS, E. A. Research methodology in management: current practices, trends, and implications for future research. Academy of Management Journal, New York, v. 40, n. 4, p. 48-55, 2000.

SCHUMPETER, J. A. Teoria do desenvolvimento econômico. 2. ed. São Paulo: Abril Cultural, 1982.

SPECTATORS on representation of Cirque du Soleil. Disponível em: <http://www.dreamstime.com/stockimages-pectators-on-representation-of-cirque-du-soleilimage13021074>. Acesso em: 26 jul. 2010.

VICO MAÑAS, A. Gestão da tecnologia e inovação. São Paulo: Érica, 1993.
Recebido: 15/08/2010

Received: 08/15/2010

Aprovado: $16 / 11 / 2010$ Approved: 11/16/2010 